\title{
Control of grain-boundary tunneling barriers in polycrystalline silicon
}

\author{
Toshio Kamiya, ${ }^{\text {a),b) }}$ Zahid A. K. Durrani, ${ }^{\text {b) }}$ and Haroon Ahmed ${ }^{\text {b) }}$ \\ Microelectronics Research Centre, University of Cambridge, Madingley Road, Cambridge CB3 OHE, United \\ Kingdom
}

(Received 3 June 2002; accepted for publication 1 August 2002)

\begin{abstract}
The effect of oxidation and annealing on the electrical properties of grain boundaries (GBs) in heavily doped polycrystalline silicon is characterized using bulk films and 30-nm-wide nanowires. Oxidation at $650-750^{\circ} \mathrm{C}$ selectively oxidizes the GBs. Subsequent annealing at $1000^{\circ} \mathrm{C}$ increases the associated potential barrier height and resistance. These observations can be explained by structural changes in the $\mathrm{Si}-\mathrm{O}$ network at the $\mathrm{GBs}$ and the competition between surface oxygen diffusion and oxidation from the GBs in the crystalline grains. A combination of oxidation and annealing may provide a method that can better control the GB potential barriers. (C) 2002 American Institute of Physics. [DOI: 10.1063/1.1509853]
\end{abstract}

The structural and electrical properties of polycrystalline silicon (poly-Si) thin films are of great interest in the design of ultralarge-scale integrated (ULSI) circuits and thin-film transistors for flat panel displays. ${ }^{1,2}$ As ULSI design rules are reduced to the nanometer scale, the poly-Si microstructure can strongly influence the device characteristics. If poly-Si grains are a few tens of nanometer in size, the material is of considerable interest for the fabrication of nanometer-scale devices such as single-electron transistors. ${ }^{3,4}$ Variation between individual grains and grain boundaries (GBs) causes nonuniformity in the electrical characteristics of different devices. It has also been reported that individual GBs have different structural and electrical properties. ${ }^{5,6}$ Thus control of the electrical properties of GBs is vital for nanometerscale devices, in which only a few grains and GBs may exist in the active region.

In this letter we discuss the effect of oxidation and thermal annealing on the electrical and structural properties of poly-Si thin films and on nanowires fabricated in these films. We observe that the film electrical conductivity $(\sigma)$ decreases nonmonotonically with an increase in oxidation temperature and that a two-stage oxidation process, followed by annealing, reduces variation in the activation energy of the conductivity $\left(E_{a}\right)$ and tunnel resistance $\left(R_{T}\right)$ in nanowire devices. We propose that oxygen atoms are incorporated selectively into the GBs and that this effect determines the electrical characteristics.

Our poly-Si film was prepared by solid-phase crystallization of 50 -nm-thick amorphous silicon at $850^{\circ} \mathrm{C}$ for 30 min. ${ }^{6}$ The films were doped $n$ type to $10^{20} / \mathrm{cm}^{3}$ using phosphorus ion implantation. Transmission electron microscopy (TEM) indicated that the grains were columnar with lateral size of $20-150 \mathrm{~nm}$ and that the GBs were no thicker than 1 $\mathrm{nm}^{7}$

The bulk film was characterized electrically using a large-area (100 $\mu \mathrm{m}$ contact spacing) transmission-line mode (TLM) test structure. Nanowire structures $(30 \mathrm{~nm}$ wide and

\footnotetext{
${ }^{a)}$ Materials and Structures Laboratory, Tokyo Institute of Technology, 4259 Nagatsuta, Midori-ku, Yokohama 226-8503, Japan; electronic mail: tkamiya@msl.titech.ac.jp

${ }^{b)}$ Also at: CREST, JST, 3-13-11 Shibuya, Tokyo 150-0002, Japan.
}

$20 \mathrm{~nm}-80 \mathrm{~nm}$ long) were used to investigate the microscopic properties over a few GBs. The nanowires were defined by electron-beam lithography in polymethyl methacrylate resist, followed by reactive-ion etching (RIE) in a 1:1 plasma of $\mathrm{SiCl}_{4}$ and $\mathrm{CF}_{4} \cdot{ }^{6}$ Ohmic contacts were formed by depositing aluminum contact pads by thermal vacuum evaporation.

We have used these test structures to characterize the effect of thermal treatment of the film. As-prepared, oxidized, thermally annealed, or oxidized and subsequently thermally annealed poly-Si films were investigated. The thermal treatment was performed after fabrication of the test structures. The oxidation was performed in a dry $\mathrm{O}_{2}$ ambient at temperatures from 600 to $1000{ }^{\circ} \mathrm{C}$ for $1 \mathrm{~h}$, except for at the $1000^{\circ} \mathrm{C}$ temperature, where the process was $15 \mathrm{~min}$. All samples were dipped in a HF solution before oxidation. This was necessary to obtain the oxidation effects that we report here. It may be because RIE etching forms an amorphous layer on the poly-Si nanowire surface, and the amorphous coverage results in slower oxygen diffusion than that through poly-Si GBs. The annealing was performed in an Ar ambient at $1000{ }^{\circ} \mathrm{C}$ for $15 \mathrm{~min}$. The electrical characteristics were measured at $25-300 \mathrm{~K}$ to extract $E_{a}$ and $R_{T}$ values.

The effect of oxidation on the film structure was characterized by measuring oxygen depth profiles with secondary ion mass spectroscopy (SIMS). This used a $\mathrm{Cs}^{+}$primary ion source and detected $\mathrm{O}^{-}$negative secondary ions. The oxygen composition was averaged over the entire film, although the local oxygen concentration may vary.

Figure 1 shows the room temperature conductivity of the films after various thermal treatments. The $\sigma$ value was estimated assuming a nominally 50-nm-thick film. When the film is annealed only, the $\sigma$ reduces slightly from 65 to 61 $\mathrm{S} / \mathrm{cm}$. TEM images show that the grain size increases during thermal annealing, ${ }^{7}$ which would usually be expected to increase the conductivity. However, it is also likely that the dopant diffuses out of the film surface and segregates into the silicon-oxide interface and the GBs, thereby lowering the carrier concentration and reducing the conductivity.

When the film is oxidized without subsequent annealing, $\sigma$ gradually decreases to $43 \mathrm{~S} / \mathrm{cm}$ as the oxidation temperature increases. This may be associated with a reduction in the 


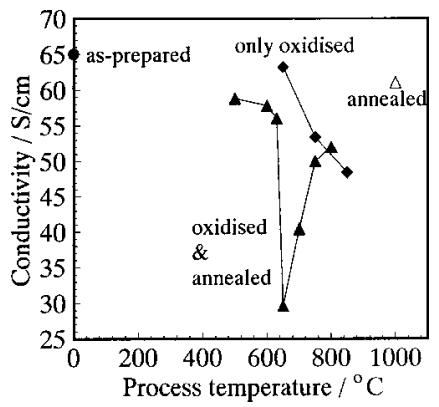

FIG. 1. Apparent conductivity of bulk films measured at room temperature. Circle: As-prepared film, open triangle: film annealed at $1000{ }^{\circ} \mathrm{C}$, diamonds: film oxidized at $650-850^{\circ} \mathrm{C}$ without subsequent annealing, closed triangles: film oxidized at $500-800{ }^{\circ} \mathrm{C}$, followed by annealing at $1000{ }^{\circ} \mathrm{C}$.

silicon layer thickness, e.g., SIMS measurements show a film oxidized at $800^{\circ} \mathrm{C}$ has a $39-\mathrm{nm}$-thick silicon layer. Therefore the actual conductivity, estimated using this value, is 64 $\mathrm{S} / \mathrm{cm}$, which is almost the same as that of the as-deposited film.

If we anneal the films after oxidation, the conductivities are reduced significantly. At even the lowest oxidation temperature of $500{ }^{\circ} \mathrm{C}$, the conductivity $(58 \mathrm{~S} / \mathrm{cm})$ is lower than in films oxidized only at $650{ }^{\circ} \mathrm{C}$, or annealed only at $1000^{\circ} \mathrm{C}$. This cannot be explained by the reduction in dopant concentration or the silicon layer thickness alone. Unusually, the conductivity behaves nonmonotonically with the oxidation temperature, falling rapidly at $650{ }^{\circ} \mathrm{C}$ and then rising as the oxidation temperature is increased up to $800^{\circ} \mathrm{C}$.

The microscopic properties of the film can be investigated using the nanowire devices. Figure 2 shows $E_{a}$ values, estimated from the slopes of Arrhenius plots of the conductance at temperatures greater than $180 \mathrm{~K}$ where thermionic emission dominates, and $R_{T}$ values estimated at temperatures less than $100 \mathrm{~K}$, where tunneling through GB potential barriers dominates since the conductance does not show tem-

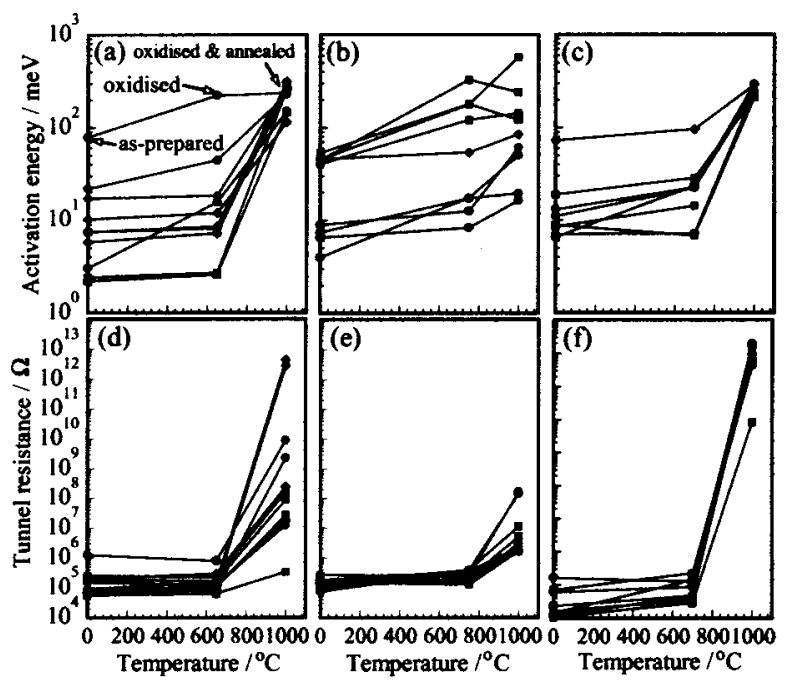

FIG. 2. Effect of oxidation and annealing on the activation energy of the conductivity (a), (b), (c) and tunnel resistance (d), (e), (f). The data at $0{ }^{\circ} \mathrm{C}$ correspond to those of as-deposited nanowires, the middle data points correspond to those of the oxidized nanowires, and the data points on the right correspond to those of the oxidized and annealed nanowires. The nanowire lengths are 20 (squares), 40 (circles) and $80 \mathrm{~nm}$ (diamonds). The oxidation temperatures are 650 (a), (d) and $750{ }^{\circ} \mathrm{C}$ (b), (e) and two-step oxidation at 650 and $7500^{\circ} \mathrm{C}(\mathrm{c}),(\mathrm{f})$. Stants in the standard oxidation model for crystalline silicon
Downloaded 11 Oct 2004 to 131.111.8.101. Redistribution subject to AlP license or copyright, see http://apl.aip.org/apl/copyright.jsp

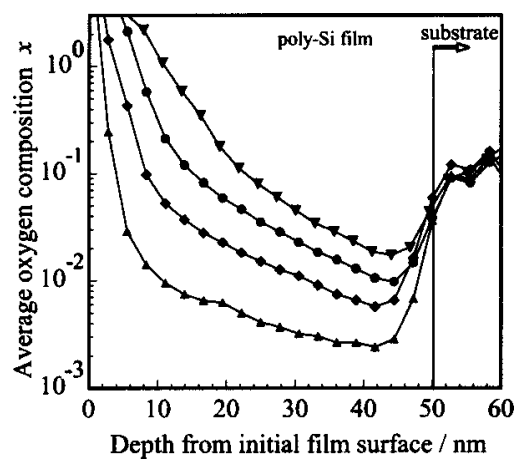

FIG. 3. Depth profile of the oxygen composition as a function of the oxidation temperature. Triangles: As-prepared film, diamonds: film oxidized at $650{ }^{\circ} \mathrm{C}$ for $1 \mathrm{~h}$, circles: film oxidized at $750{ }^{\circ} \mathrm{C}$ for $1 \mathrm{~h}$, inverted triangles: film oxidized at $800^{\circ} \mathrm{C}$ for $1 \mathrm{~h}$.

perature dependence. We show measurements from asdeposited, oxidized, and oxidized/annealed nanowires. In the measurements in Fig. 2, the Arrhenius plots are straight lines at $>180 \mathrm{~K}$ and the $E_{a}$ value reflects the GB potential barrier height $\left(V_{B}\right)$.

The $E_{a}$ and $R_{T}$ values in as-deposited nanowires vary due to differences in the GB structure and $V_{B}$ along the conduction path in different devices. ${ }^{6}$ The $R_{T}$ value does not change significantly after simple oxidation. However, subsequent annealing at $1000{ }^{\circ} \mathrm{C}$ increases the $R_{T}$ value, and this effect is larger for the $650^{\circ} \mathrm{C}$ oxidation than for the nano wires oxidized at other temperatures. There is greater scatter in the $R_{T}$ value in nanowires annealed after $650^{\circ} \mathrm{C}$ oxidation. Most $E_{a}$ values do not increase significantly with simple oxidation at $650{ }^{\circ} \mathrm{C}$ although there is an increase in some samples with simple oxidation at $750{ }^{\circ} \mathrm{C}$. After annealing, the values mainly tend to increase, and this is clearer for oxidation at $650{ }^{\circ} \mathrm{C}$. There is significant scatter in the values after annealing for oxidation at $750^{\circ} \mathrm{C}$. If the nanowires are oxidized at $1000^{\circ} \mathrm{C}$ (not shown) the behavior is similar to oxidation at $750{ }^{\circ} \mathrm{C}$. However, two-step oxidation at $650{ }^{\circ} \mathrm{C}$ for $1 \mathrm{~h}$ and at $750^{\circ} \mathrm{C}$ for $1 \mathrm{~h}$ before annealing narrows the distribution of $E_{a}$ and $R_{T}$ even compared within as-deposited nanowires.

Figure 3 shows a SIMS depth profile of oxygen composition $x$ of $\mathrm{SiO}_{x}$ in the film. There is an increase in $x$ with the oxidation temperature. Gradient changes in each profile form three distinct regions: (1) surface oxide, where $x$ is greater than the stoichiometric value in $\mathrm{SiO}_{2}$ of 2 due to surface contamination, (2) oxygen diffusion from the surface oxide, where the gradient is large, and (3) a deep region with a small gradient. The change in gradient cannot be explained by a simple oxygen diffusion model, ${ }^{8}$ implying that other oxygen diffusion paths exist. It is known that impurity diffusion in GBs is greater than in crystalline grains. ${ }^{7,9,10} \mathrm{We}$ therefore attribute the third region to oxygen diffusion in the GBs.

Table I shows the silicon thickness consumed by the surface oxide $\left(d_{s}\right)$ and the GB oxygen diffusion length $\left(l_{\mathrm{GB}}\right) . l_{\mathrm{GB}}$ corresponds to the length in region (3), Fig. 3, where $x$ falls to half of the initial value. $l_{\mathrm{GB}}$ does not change markedly with the oxidation temperature whereas $d_{s}$ increases. It is known that either the parabolic or linear con- 
TABLE I. Thickness of the silicon consumed by the surface oxide $\left(d_{s}\right)$ and diffusion length in GBs $\left(l_{\mathrm{GB}}\right)$ as a function of the oxidation temperature $\left(T_{\mathrm{ox}}\right)$. No subsequent thermal annealing is used.

\begin{tabular}{lcc}
\hline \hline $\begin{array}{l}T_{\mathrm{ox}} \\
\left({ }^{\circ} \mathrm{C}\right)\end{array}$ & $\begin{array}{c}d_{s} \\
(\mathrm{~nm})\end{array}$ & $\begin{array}{c}l_{\mathrm{GB}} \\
(\mathrm{nm})\end{array}$ \\
\hline 650 & 2.7 & 7.1 \\
750 & 5.0 & 7.2 \\
800 & 11.3 & 6.9 \\
\hline \hline
\end{tabular}

exhibit thermally activated behavior with large activation energies of 1.2-2.0 eV. ${ }^{8}$ However, in disordered phases like amorphous silicon or GBs, the impurity diffusion constant varies according to the structure, ${ }^{11}$ and almost zero activation energy is possible. ${ }^{12}$ The interstitial and defect states in the GBs in our film can result in a low activation energy for impurity diffusion. The GBs are then oxidized selectively at lower temperatures where the growth of surface oxide is suppressed.

We propose the following oxidation model for our poly-Si films. Simple oxidation forms a surface oxide and diffuses oxygen atoms into the GBs. This does not form silicon oxide at the GBs with a potential barrier high enough to effect conduction (Fig. 2). However, subsequent hightemperature annealing may reconfigure the oxidized GB structure. This has been observed in silicon suboxide, where the silicon-rich bonding structure $\mathrm{Si}_{-} \mathrm{Si}_{4-n} \mathrm{O}_{n}(n<4)$ forms the major portion of the suboxide. High-temperature annealing can convert some parts of this to a $\mathrm{Si}-\mathrm{O}_{4}$ tetrahedral structure $^{13}$ or cause phase separation into nanocrystalline silicon and silicon dioxide. ${ }^{14}$ In our films, the GB volume may be limited for nanocrystalline silicon formation, and a $\mathrm{Si}-\mathrm{O}_{4}$ structure may form locally. In addition, such suboxide structures can persist even at $1000^{\circ} \mathrm{C} .{ }^{13} \mathrm{We}$ suggest that the GBs are a mixture of $\mathrm{Si}-\mathrm{O}_{4}$ and silicon-rich structures, the former with an energy gap close to silicon dioxide and the latter with a lower energy gap. These energy gaps and the local trapped charge create potential barriers at the GBs, and a mix of these structures leads to a local distribution in $V_{B}$. Carriers flow over the lowest potential barrier region. Therefore, the $E_{a}$ value after oxidation/annealing depends ultimately on the oxygen concentration in the GBs, which is controlled by the oxidation temperature.

The drop in the $\sigma$ around $650^{\circ} \mathrm{C}$ for oxidized and annealed films (Fig. 1) is explained as follows. If the oxidation temperature is $<650{ }^{\circ} \mathrm{C}$, low oxygen diffusivity causes a low oxygen concentration in the GBs and the film conductivity is unaffected. At $\sim 750^{\circ} \mathrm{C}$, the activation energy for crystalline silicon oxidation is overcome, and the grains are oxidized from the GBs. This increases the oxidized GB volume and reduces $x$ in the GB, lowering $V_{B}$ and increasing $\sigma$. This is supported by the larger $E_{a}$ and $R_{T}$ values after annealing in the nanowires oxidized at $650{ }^{\circ} \mathrm{C}$, compared to at $750^{\circ} \mathrm{C}$ (Fig. 2), and implies that $V_{B}$ is higher even though the average oxygen concentration is lower (Fig. 3). At an intermediate oxidation temperature, oxygen can diffuse into GBs from the atmosphere while the increase in the thickness of the oxidized GBs is not large. Consequently, the highest GB potential barrier is formed at temperatures between 650 and $750^{\circ} \mathrm{C}$, with a corresponding fall in the film conductivity.

In conclusion, we have observed enhancement of the GB potential barriers in poly-Si thin films by oxidation and annealing. The selectivity of GB oxidation is increased at lower oxidation temperatures. Subsequent high-temperature annealing is necessary to form high potential barriers. This behavior is explained by structural changes in the $\mathrm{Si}-\mathrm{O}$ network and the competition between oxygen diffusion from the film surface and oxidation from the GBs in the crystalline grains. The process may provide a means by which to obtain consistent properties of GBs in poly-Si.

The authors would like to thank Dr. H. Mizuta and K. Furuta of the Hitachi-Cambridge Laboratory and Professor M. Yoshimura of Tokyo Institute of Technology for helpful discussions. This work was supported by the Japan Science and Technology Agency through the CREST program.

${ }^{1}$ K. Nakazato, K. Itoh, H. Mizuta, and H. Ahmed, Electron. Lett. 35, 848 (1999).

${ }^{2}$ T. Sameshima, J. Non-Cryst. Solids 227-230, 1196 (1998).

${ }^{3}$ K. Yano, T. Ishii, T. Hashimoto, T. Kobayashi, F. Murai, and K. Seki, IEEE Trans. Electron Devices 41, 1628 (1994).

${ }^{4}$ A. C. Irvine, Z. A. K. Durrani, and H. Ahmed, Appl. Phys. Lett. 73, 1113 (1998).

5 J. W. Tringe and J. D. Plummer, J. Appl. Phys. 87, 7913 (2000).

${ }^{6}$ Y. Furuta, H. Mizuta, K. Nakazato, Y. T. Tan, T. Kamiya, Z. A. K. Durrani, H. Ahmed, and K. Taniguchi, Jpn. J. Appl. Phys., Part 2 40, L615 (2001).

${ }^{7}$ Y. T. Tan, Z. A. K. Durrani, and H. Ahmed, J. Appl. Phys. 89, 1262 (2001).

${ }^{8}$ S. M. Sze, VLSI Technology (McGraw-Hill, Singapore, 1988).

${ }^{9}$ Y. Furuta, H. Mizuta, K. Nakazato, T. Kamiya, Y. T. Tan, Z. A. K. Durrani, and K. Taniguchi, Jpn. J. Appl. Phys., Part 1 41, 2675 (2002).

${ }^{10}$ T. Kamins, Polycrystalline Silicon for Integrated Circuits and Displays, 2nd ed. (Kluwer Academic, Dordrecht, 1998).

${ }^{11}$ J. J. Perez-Bueno, R. Ramirez-Bon, Y. V. Vorobiev, F. Espinoza-Beltran, and J. Gonzalez-Hernandez, Thin Solid Films 379, 57 (2000).

${ }^{12}$ S. Satoh, I. Matsuyama, and K. Susa, J. Non-Cryst. Solids 190, 206 (1995).

${ }^{13}$ F. Iacona, S. Lombardo, and S. U. Campisano, J. Vac. Sci. Technol. B 14, 2693 (1996).

${ }^{14}$ L. Pavesi, L. Dal Negre, C. Mazzoleni, G. Franzo, and F. Priolo, Nature (London) 408, 440 (2000). 